\title{
A Comparison of the Antiatherogenic Effects of Probucol and of a Structural Analogue of Probucol in Low Density Lipoprotein Receptor-deficient Rabbits
}

\author{
Joachim Fruebis, * Daniel Steinberg, * Hans A. Dresel, ${ }^{\star}$ and Thomas E. Carew *t \\ *University of California, San Diego, Department of Medicine, La Jolla, California 92093; and ${ }^{\ddagger}$ Department of Atherosclerosis \\ Research, Boehringer Mannheim GmbH, D-68305 Mannheim, Germany
}

\begin{abstract}
The efficacies of probucol and a close structural analogue as antioxidants in the prevention of atherogenesis in LDL receptor-deficient rabbits were compared. The antioxidant potency of the analogue in vitro was equal to that of probucol. Its biological availability was much greater: almost comparable concentrations in total plasma were achieved by feeding $1 \%$ probucol (wt/wt) and $0.05 \%$ analogue (wt/wt). Total plasma concentrations were comparable, but the concentration of probucol within the LDL fraction was about twice that of the analogue. Probucol slowed lesion progression by almost $50 \%$, confirming earlier reports; the analogue; however, showed no detectable inhibitory effect on atherogenesis. Resistance of LDL to oxidation was measured at the end of the study by incubating it with $\mathrm{Cu}^{2+}$ and measuring the rate of diene conjugation. Probucol prolonged diene conjugation lag time from the control value of 130 min to values $>1,000$ min. The analogue approximately tripled the lag time (mean, $410 \mathrm{~min}$ ) and yet failed to slow the atherogenic process. The results suggest that LDL resistance to oxidation must reach some threshold level before there is significant protection against atherogenesis. However, probucol has additional biological effects, possibly not shared by the analogue, that could contribute to its antiatherogenic potential. (J. Clin. Invest. 1994. 94:392-398.) Key words: atherosclerosis - macrophages • oxidation • antioxidant $\cdot$ drug therapy
\end{abstract}

\section{Introduction}

Many lines of evidence, based on studies in cell culture and in experimental animals, suggest that the conversion of native LDL to oxidatively modified LDL is a critical step in the atherogenic process $(1,2)$. Probably the most compelling evidence in favor of the oxidative modification hypothesis of atherosclerosis is that antioxidants have been shown in six of nine published

\footnotetext{
${ }^{\dagger}$ Deceased.

Address correspondence to Daniel Steinberg, M.D., Ph.D., University of California, San Diego, Department of Medicine, 9500 Gilman Drive, Department 0682, Basic Science Building, Room 1080, La Jolla, CA 92093.

Dr. H. A. Dresel's present address is Progen Biotechnik, Im Neuenheimer Feld 519, 69120 Heidelberg, Germany.

Received for publication 29 November 1993 and in revised form 9 March 1994.
}

J. Clin. Invest.

(c) The American Society for Clinical Investigation, Inc. 0021-9738/94/07/0392/07 \$2.00

Volume 94 , July $1994,392-398$ trials (3-11) to slow the rate of progression of experimental atherosclerosis by more than $50 \%$ in LDL receptor-deficient rabbits (3-5) and in cholesterol-fed rabbits (7-9). One study of vitamin $\mathrm{E}$ in cholesterol-fed monkeys gave marginal results (11) and one rabbit study was negative (10). A majority of these studies made use of probucol as the antioxidant $(3-6,9$, 10 ). Unfortunately probucol has a cholesterol-lowering effect and several additional biological effects that could very well contribute to or even be primarily responsible for the antiatherogenic effects observed. In some studies the cholesterol-lowering effect of probucol has been taken into account by treating the control group in such a way as to match cholesterol levels (3); in other studies this has not been done (4-6). The additional biological effects that may come into play include the ability of probucol to inhibit release of IL-1 (12), to increase the expression of cholesterol ester transfer protein $(13,14)$, and to act at an intracellular level to modify oxidative metabolism (15). The possibility that probucol's antiatherogenic effects are mainly related to its action as an antioxidant is strengthened by the fact that two other antioxidants have been shown to be effective against experimental atherosclerosis. Butylated hydroxytoluene (BHT) ${ }^{1}$ was shown by Björkhem and co-workers to inhibit atherosclerosis in cholesterol-fed rabbits (7); $N, N^{\prime}-$ diphenylphenylenediamine (DPPD) was shown to be effective, again in cholesterol-fed rabbits, by Sparrow and co-workers (8). BHT is structurally closely related to probucol but it does not share the cholesterol-lowering effects of probucol. Thus, the Björkhem study is not confounded by the issue of cholesterollowering. On the other hand, BHT has not been tested to see whether it shares some of the other biological properties of probucol. Because of its structural similarity it may very well do so. DPPD is structurally quite different from BHT or probucol and again does not have any cholesterol-lowering effect. The fact that Sparrow and co-workers obtained a result rather similar to that obtained using probucol is consistent with the possibility that probucol works primarily as an antioxidant. However, it does not prove it beyond doubt. Thus there is a need to carry out studies with additional antioxidant compounds and to show unambiguously that the protective effects are due to the antioxidant effect. The present study explores the effects of a new antioxidant, a close structural analogue of probucol (Fig. 1).

\section{Methods}

Rabbits and diets. We studied $27 \mathrm{LDL}$ receptor-deficient Watanabe heritable hyperlipidemic (WHHL) rabbits ( 12 females and 15 males)

1. Abbreviations used in this paper: BHT, butylated hydroxytoluene; DPPD, $N, N^{\prime}$-diphenylphenylenediamine; TC, tyramine cellobiose; WHHL rabbit, Watanabe heritage hyperlipidemic rabbit. 

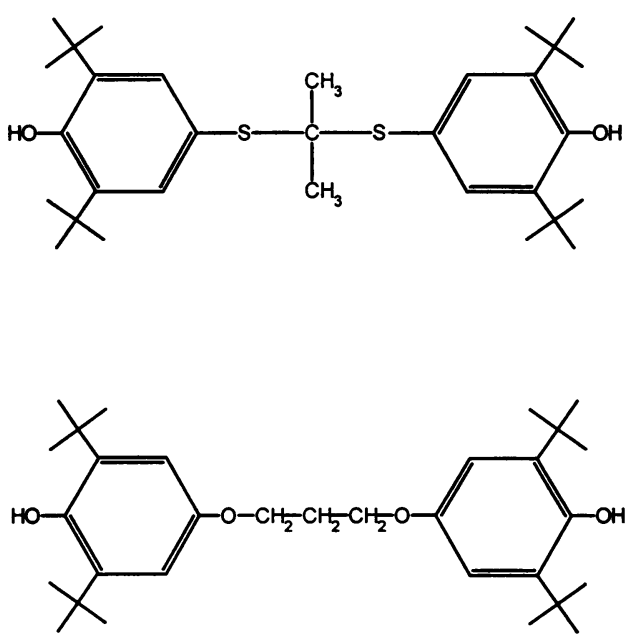

Figure 1. Chemical structures of probucol (top) and bis(3,5-diterbutyl4-hydroxyphenylether)propane (BM15.0639) (bottom).

from four litters. The animals were divided into three groups, a control group $(n=10)$, a BM15.0639 group $(n=11)$, and a probucol group $(n=6)$. The groups were matched for litter, gender, and plasma cholesterol. Probucol (a gift from Merrell Dow Pharmaceuticals, Inc.) was added to the chow at a concentration of $1 \%(\mathrm{wt} / \mathrm{wt})$. BM15.0639 [bis(3,5-di-tert-butyl-4-hydroxyphenylether)propane], a gift from Boehringer Mannheim, Mannheim, Germany is much more bioavailable than probucol, yielding similar plasma levels at $1 / 20$ th the dose of probucol. Therefore it was fed at a concentration of $0.05 \%$ (wt/wt). The drugs were added to the chow in diethyl ether and the control chow was similarly treated with plain solvent. The chow was dried for several days before use. The rabbits were fed the diets for $30 \mathrm{wk}$ starting at 13 wk of age. The daily chow ration was gradually increased from 80 to $120 \mathrm{~g}$ as the rabbits grew. Extensive studies on the pharmacology and toxicology of BM15.0639 in rabbits were conducted by Boehringer Mannheim. No adverse effects at the doses used were found (H.A. Dresel, unpublished data), and none were found in the present studies.

Plasma lipids and determination of drug levels. Plasma samples were obtained every 2-4 wk after an overnight fast, and cholesterol levels were determined using an automated enzymatic technique (Boehringer Mannheim Diagnostics, Indianapolis, IN). The samples were used to determine drug levels in plasma. The concentrations of probucol and of BM15.0639 were determined using the same HPLC assay. In brief, plasma samples were extracted with methanol/acetone, 3:2 (vol/ vol), with addition of 2-pentanone-bis(3,5-di-t-butyl-4-hydroxyphenyl) mercaptole as internal standard, and partitioned into heptane. The samples were analyzed by HPLC on $\mathrm{a}_{18}$-reversed phase column eluted with acetonitrile/heptane/0.1 M ammonium acetate, 92:6:2 (vol/vol). Absorption at $254 \mathrm{~nm}$ for probucol and at $234 \mathrm{~nm}$ for BM15.0639 was measured. The determination of drug levels in LDL was done using the same method. The concentration of probucol and BM15.0639 in tissue was determined by HPLC after enzymatically digesting, homogenizing, and extracting the tissue (16). In brief, $100 \mathrm{mg}$ of tissue was incubated with $1 \mathrm{ml}$ bacterial collagenase (type $I, 5 \mathrm{mg} / \mathrm{ml}$ ) and $0.5 \mathrm{ml}$ porcine lipase $(2 \mathrm{mg} / \mathrm{ml})$ for $3 \mathrm{~h}$ at $37^{\circ} \mathrm{C}$. Enzymes were from Worthington Biochemicals (Freehold, NJ). To each sample was added $50 \mu \mathrm{l}$ of ascorbic acid $(10 \mathrm{mg} / \mathrm{ml})$. After this digestion the samples were homogenized using a ground-glass pestle-tube system. Internal standard was added and the sample was extracted twice with hexane. The combined hexane phases were dried under a stream of nitrogen. The extracted material was resolubilized in HPLC mobile phase and analyzed as described for plasma drug levels.

Isolation of $L D L$ and $L D L$ modification. LDL $(d=1.021-1.060 \mathrm{~g} /$ $\mathrm{ml}$ ) was isolated by sequential ultracentrifugation from plasma collected into EDTA after an overnight fast (17). Protein was determined by the method of Lowry et al. (18) with BSA as a standard. At the end of the isolation LDL was extensively dialyzed against PBS containing $2 \mathrm{mM}$ EDTA. LDL was subjected to prooxidative conditions to study its resistance to oxidation as follows: preceding the use of LDL, EDTA was removed by dialysis against PBS. Unlabeled or ${ }^{125} \mathrm{I}$-labeled LDL was diluted in Ham's F-10 medium ( $100 \mu \mathrm{g} \mathrm{LDL}$ protein $/ \mathrm{ml}$ ) and then was incubated in $60-\mathrm{mm}$ plastic dishes with confluent rabbit aortic endothelial cells for $18 \mathrm{~h}$ or incubated in PBS in the presence of 5-10 $\mu \mathrm{M}$ $\mathrm{CuSO}_{4}$. The formation of conjugated dienes was measured as the increase in absorption at $234 \mathrm{~nm}$. Lag times were determined graphically as the timepoint at which the tangent to the curve during the maximum slope of the propagation phase intercepted the time axis. Absorption at the beginning of the reaction was set to zero. Thiobarbituric acidreactive substances were measured as an index of the degree of lipid peroxidation (19). The extent of LDL oxidation was also assessed in terms of the increase in its rate of degradation by macrophages: $10 \mu \mathrm{g}$ of ${ }^{125} \mathrm{I}-\mathrm{LDL}$ (native or modified) in $0.5 \mathrm{ml}$ DME was added to mouse peritoneal macrophages in 24-well dishes and incubated at $37^{\circ} \mathrm{C}$ for 5 h. Trichloroacetic acid-soluble radioactivity in the medium and cellassociated radioactivity were then determined.

Extent of aortic lesions. Each rabbit was given 1,000 IU heparin and then was deeply anesthetized with sodium pentobarbital $(50 \mathrm{mg} /$ $\mathrm{kg}$ ). The systemic circulation was perfused with 2 liters of isotonic PBS containing $2 \mathrm{mM}$ EDTA through a large-bore cannula introduced into the apex of the left ventricle while collecting the effluent from the severed right ventricle. The aorta was then fixed in situ with halfstrength Karnowsky's solution for 20-25 min. A perfusion pressure of $80 \mathrm{~mm} \mathrm{Hg}$ was maintained during the entire procedure, using large elevated reservoirs. The entire aorta was removed and cleaned of loose adventitial tissue. The thoracic and abdominal aortas were divided 5 $\mathrm{mm}$ proximal to the celiac artery. Each segment was opened longitudinally and fixed in half-strength Karnowsky's for an additional $24 \mathrm{~h}$. The aortas were stained with Sudan IV, pinned flat on wax beds, and covered with PBS. They were then photographed and digitally recorded using a Cohu solid-state camera connected to a personal computer via a datatechnology 2851 frame grabber board. The captured image was processed using image pro II software (Media Cybernetics, Inc., Silver Spring, MD). The areas of sudanophilic lesions and the total area of each aortic segment were determined (20). The extent of lesions was expressed as percent of total aortic surface area involved.

Metabolic studies. In subsets of four rabbits from each of the three different treatment groups, arterial LDL degradation rates were determined at killing. LDL was isolated from pools of plasma of each group as described above. The LDL was first iodinated conventionally with ${ }^{125}$ I using 1,3,4,6-tetrachloro-3 $\alpha, 6 \alpha$-diphenylglycouril (Iodogen; Pierce Chemical Co. Rockford, IL). It was then covalently linked to ${ }^{131} \mathrm{I}-$ tyramine cellobiose $\left({ }^{131} \mathrm{I}-\mathrm{TC}\right)$, a lysosomally trapped tracer, with cyanuric chloride as described (21). After dialysis against PBS containing $2 \mathrm{mM}$ EDTA, $<1 \%$ of the radioactivity of each isotope was soluble in $10 \%$ (wt/vol) trichloroacetic acid. Radioactivity extractable into chloroform/methanol, $1: 1$ ( $\mathrm{vol} / \mathrm{vol}$ ), was $2.41 \pm 0.34 \%$ for ${ }^{125} \mathrm{I}$ and $1.47 \pm 0.33 \%$ for ${ }^{131} \mathrm{I}$. The specific activities of ${ }^{125} \mathrm{I}$ and ${ }^{131} \mathrm{I}-\mathrm{TC}$ ranged from 281 to 462 and 65.4 to $126 \mathrm{cpm} / \mathrm{ng}$ protein, respectively. The LDL was used 2-3 d after labeling, which was 3-4 d after initial isolation. The doubly labeled LDL $\left(6.97 \pm 1.29 \times 10^{8} \mathrm{cpm}\right.$ of ${ }^{125} \mathrm{I}$ and $1.80 \pm 0.42 \times 10^{8} \mathrm{cpm}$ of ${ }^{131} \mathrm{I}$ ) was injected intravenously after the rabbits had been injected with $3 \mathrm{mg}$ of $\mathrm{NaI}$ to prevent uptake of radioiodide by the thyroid. The animals received homologous LDL. The plasma decay of labeled LDL was followed over $72 \mathrm{~h}$ by obtaining 12 serial samples of blood beginning at $10 \mathrm{~min}$ after injection. At killing the systemic circulation was perfused with PBS; the aortas were fixed in situ, dissected, stained, and photographed; and the sudanophilic lesion area was determined as described above. The aortic arch was separated from the descending thoracic aorta 1-2 mm below the ductus scar. Sudan positive atherosclerotic lesions and negative nonlesioned areas were cut out of each aortic segment and weighed. The ${ }^{125} \mathrm{I}$ and ${ }^{131} \mathrm{I}$ contents of tissue and plasma samples were measured in a well-type $\gamma$-scintillation-counter (Compu Gamma; LKB Instruments Inc., Gaithersburg, MD) with cor- 
Table I. Inhibition of $\mathrm{Cu}^{2+}$ - and Endothelial Cell-promoted LDL Oxidation In Vitro

\begin{tabular}{|c|c|c|}
\hline Additions & TBARS & $\begin{array}{c}\text { Degradation by } \\
\text { macrophases }\end{array}$ \\
\hline & $n m o l ~ M D A / m l$ & $\begin{array}{c}\mu g / 5 h r * m g \\
\text { protein }\end{array}$ \\
\hline Native LDL & 1.4 & 0.8 \\
\hline LDL incubated with endothelial cells & 40 & 8.85 \\
\hline $1 \mu \mathrm{M}$ probucol & 42 & 9.15 \\
\hline $2.5 \mu \mathrm{M}$ probucol & 37 & 7.30 \\
\hline $5 \mu \mathrm{M}$ probucol & 6 & 1.20 \\
\hline None & 39 & 9.00 \\
\hline $1 \mu \mathrm{M}$ BM15.0639 & Nondetectable & 1.05 \\
\hline $2.5 \mu \mathrm{M}$ BM15.0639 & Nondetectable & 1.45 \\
\hline $5 \mu \mathrm{M}$ BM15.0639 & Nondetectable & 1.13 \\
\hline None & 48 & 6.75 \\
\hline \multicolumn{3}{|l|}{ LDL incubated with $\mathrm{Cu}^{2+}$} \\
\hline $1 \mu \mathrm{M}$ probucol & 52 & 6.05 \\
\hline $2.5 \mu \mathrm{M}$ probucol & 52 & 4.65 \\
\hline $5 \mu \mathrm{M}$ probucol & 23 & 0.86 \\
\hline None & 50 & 6.45 \\
\hline $1 \mu \mathrm{M}$ BM15.0639 & 55 & 3.95 \\
\hline $2.5 \mu \mathrm{M}$ BM15.0639 & 41 & 0.95 \\
\hline $5 \mu \mathrm{M}$ ВM15.0639 & 6 & 1.00 \\
\hline
\end{tabular}

${ }^{125} \mathrm{I}-\mathrm{LDL}(100 \mu \mathrm{g} / \mathrm{ml})$ was incubated for $18 \mathrm{~h}$ with either $5 \mu \mathrm{M} \mathrm{Cu}^{2+}$ or endothelial cells in F-10 medium. The extent of LDL oxidation in the presence of probucol or BM15.0639 was then assessed by measuring thiobarbituric acid-reactive substances (TBARS) and the rate of degradation by macrophages.

rections for overlap of the energy spectra of the two isotopes, for background activity, and for isotopic decay. The rate of LDL catabolism in the whole body and in aortic tissues was then determined as described in detail previously (22). The procedure is based on the nearly complete lysosomal retention of TC after TC-LDL degradation, i.e., TC acts as a "trapped ligand." The arterial content of conventionally iodinated ${ }^{125}$ I-labeled LDL, i.e. undegraded native LDL, was used to correct for ${ }^{131}$ I-TC covalently bound to undegraded LDL within the artery, thus allowing assessment of the fraction of LDL degraded. ${ }^{125}$ I derived from degradation products of conventionally labeled LDL are not trapped intracellularly and are not retained in tissue fixed with half-strength Karnowsky's (22, 23).

Histology. For immunohistochemistry, serial 5- $\mu \mathrm{m}$ thick sections were cut from the paraffin-embedded aortae and stained with RAM-11 (24), a monoclonal antibody specific for rabbit macrophages; or HHF35 (25), a monoclonal antibody against actin; or MDA2 (26) a mouse monoclonal antibody against MDA-LDL as described in detail previously (27). We used an avidin-biotin-alkaline phosphatase system (Vector Laboratories, Inc., Burlingame, CA) for visualization. To investigate lipid distribution in tissue, $10-\mu \mathrm{m}$ thick frozen sections were cut from OCT-embedded aortae. Lipids were stained with $0.4 \%$ Sudan black B in propylene glycol (28).

Statistical analysis. All results are expressed as mean \pm SEM. Differences between treatment groups are assessed by analysis of variance and covariance. The statistical analyses were performed using BMDP statistical software (29).

\section{Results}

Inhibition of $L D L$ oxidation in vitro. The potencies of BM15.0639 and probucol in the inhibition of LDL oxidation in vitro were compared. As shown in Table I, probucol showed a partial inhibition of LDL oxidation by endothelial cells at 2.5 $\mu \mathrm{M}$ and almost completely blocked oxidation at $5 \mu \mathrm{M}$. The

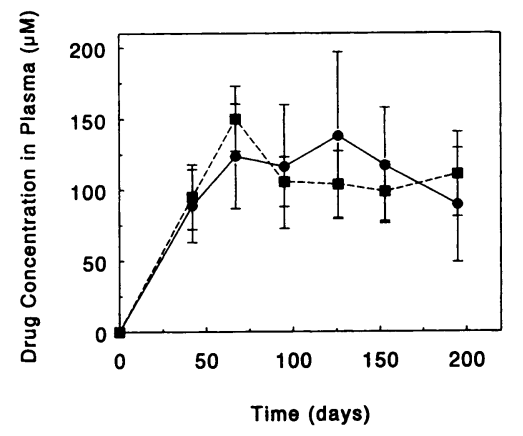

Figure 2. Plasma concentrations of BM15.0639 and of probucol in WHHL rabbits as a function of days of treatment. Plasma samples of animals were taken at different timepoints and analyzed for drug content by HPLC (see Methods).

The data shown are mean plasma concentrations \pm SEM. - - $\bullet-$, $\operatorname{BM} 15.0639(n=11)$; $---\mathbf{D}---$, probucol $(n=6)$.

analogue was even more potent in this in vitro test system, inhibiting oxidation of LDL almost completely even at $1 \mu \mathrm{M}$.

Oxidation induced by incubation with copper ions was also inhibited effectively by both compounds. Probucol again showed inhibition at $2.5 \mu \mathrm{M}$ and almost completely blocked at $5 \mu \mathrm{M}$; the analogue showed a definite effect a $1 \mu \mathrm{M}$ and was completely inhibitory at $2.5 \mu \mathrm{M}$. It should be noted that the concentrations of drug actually reached within the LDL particles under these conditions is not known; the drugs were simply added in ethanolic solution but no measurements of the fraction entering the LDL particles were made.

Both drugs were also shown to inhibit LDL oxidation assessed in terms of increased electrophoretic mobility and the ability of the oxidatively modified LDL to induce accumulation of cholesterol esters in macrophages. These results were consonant with those described above, i.e., the analogue had a somewhat greater potency than that of probucol itself (data not shown).

Plasma drug levels and degree of protection of plasma LDL against oxidative modification ex vivo. Previous studies of pharmacodynamics at Boehringer Mannheim laboratories had shown that BM15.0639 was much more readily absorbed than probucol (H. Dresel, personal communication). In fact, comparable blood levels were reached at $1 / 20$ th the dose of probucol. As shown in Fig. 2, total plasma concentrations of the analogue and of probucol were almost exactly the same when probucol was included in the diet at $1 \%(\mathrm{w} / \mathrm{w})$ and the analogue at $0.05 \%(w / w)$. However, even though the mean total plasma concentrations of the two drugs were similar, the concentration of probucol in the LDL particles was approximately twice as high as that of the analogue: $27.8 \mathrm{nmol}$ probucol/mg LDL protein versus $12 \mathrm{nmol}$ of analogue $/ \mathrm{mg} \mathrm{LDL}$ at $30 \mathrm{wk}$. Both drugs were transported almost exclusively in lipoproteins, i.e., almost none was found in the 1.21 bottom fraction. The higher concentrations of probucol per LDL particle reflected in part the decrease in total plasma lipoproteins in the probucol-treated group (i.e., the drug was distributed among a smaller total number of lipoprotein particles) and the fact that a higher percentage of the total plasma lipids was found in the LDL fraction in the probucol-treated groups (i.e., the VLDL dropped to a greater extent than did the LDL so that the fraction of total plasma lipids represented by the LDL increased as did its share of the lipophilic drug).

LDL was isolated from the plasma at the end of the feeding period and tested for its resistance to oxidation ex vivo. The 


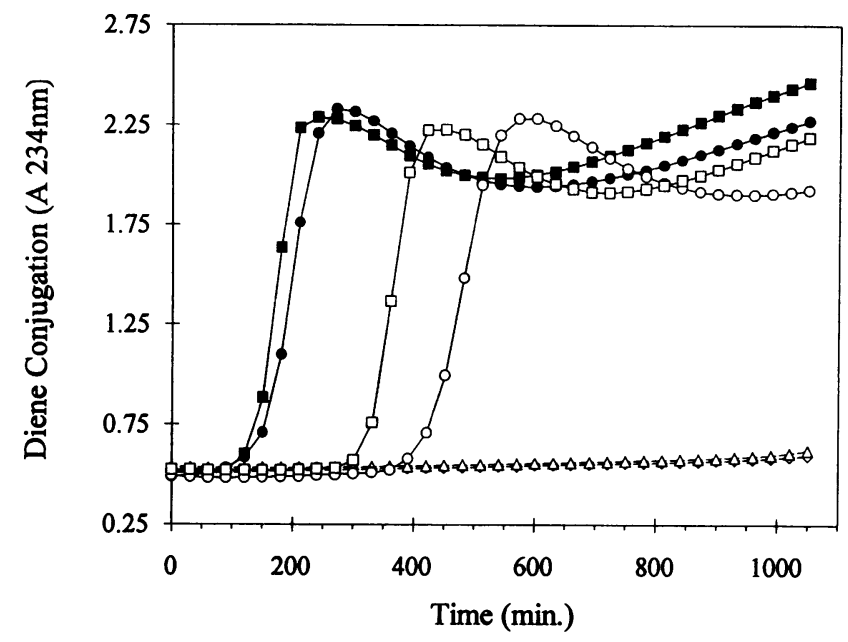

Figure 3. Real-time rate of $\mathrm{Cu}^{2+}$-catalyzed diene conjugation in plasma LDL isolated from control rabbits and rabbits treated with BM15.0639 or probucol. LDL isolated from rabbits after $30 \mathrm{wk}$ of treatment was pooled and subjected to $\mathrm{Cu}^{2+}$-promoted oxidation. The formation of conjugated dienes was measured by measuring the absorption at $234 \mathrm{~nm}$. Control LDL $+10 \mu \mathrm{M} \mathrm{Cu}^{2+}(--\mathbf{-}-)$, control $\mathrm{LDL}+5 \mu \mathrm{M} \mathrm{Cu}^{2+}(---\infty), \mathrm{BM} 15.0639+10 \mu \mathrm{M}$ $\mathrm{Cu}^{2+}(--\square-\longrightarrow), \mathrm{BM} 15.0639+5 \mu \mathrm{M} \mathrm{Cu}^{2+}(--\mathrm{O}--)$, probucol $+10 \mu \mathrm{M} \mathrm{Cu}^{2+}(---\triangle---)$, probucol $+5 \mu \mathrm{M} \mathrm{Cu}^{2+}$ $(---\diamond---)$.

samples were incubated in the presence of 5 or $10 \mu \mathrm{M} \mathrm{CuSO}_{4}$ and the rate of conjugated diene formation was followed by measuring absorption at $234 \mathrm{~nm}$. As shown in Fig. 3, LDL from animals treated with probucol was almost completely protected against oxidative modification for over 1,000 min under these conditions. In contrast, LDL from the animals treated with the analogue, although showing a definite extension of lag time compared with control LDL, was much less well protected. The diene conjugation lag time for the analogue-treated animals was $313 \mathrm{~min}$ in the presence of $10 \mu \mathrm{M}$ copper and $410 \mathrm{~min}$ in the presence of $5 \mu \mathrm{M}$ copper. The control samples showed lag times of only a little over $100 \mathrm{~min}$.

To determine whether the results obtained at the termination of the study were representative or not, we studied a small number of animals fed the drugs for $14 \mathrm{~d}$ or for $9 \mathrm{wk}$. As shown in Table II, the results were very similar to those obtained at the end of the study, i.e., the lag time for diene conjugation was prolonged to a much greater extent in the LDL from probucol-treated animals than in the LDL from the analogue-treated animals and both were considerably longer than the value in the controls.

Effects of treatment. None of the animals showed any signs of toxicity and the weight gain in all groups was similar. Total plasma cholesterol in the untreated controls was $788 \pm 113 \mathrm{mg} /$ dl during the studies. The analogue did not decrease plasma cholesterol at all $(745 \pm 102 \mathrm{mg} / \mathrm{dl})$ but probucol, as expected, did $(581 \pm 115 \mathrm{mg} / \mathrm{dl}$ during the study). Lipoprotein profiles, carried out at time zero and after $18 \mathrm{wk}$ of feeding showed that HDL accounted for only $<2 \%$ of the total plasma cholesterol and there were no significant differences in HDL levels between the probucol-treated and the analogue-treated groups; both showed a drift downward during the course of the study. The LDL fraction accounted for $27 \%$ of the total plasma cholesterol
Table II. Effects of Probucol and of BM15.0639 on $\mathrm{Cu}^{2+}$-catalyzed Oxidation of Plasma LDL after 2, 9, and 30 wk of Treatment

\begin{tabular}{lccc}
\hline & \multicolumn{3}{c}{ Lag times } \\
\cline { 2 - 4 } Length of treatment & Control & BM15.0639 & Probucol \\
\hline & $\min$ & $\min$ & $\min$ \\
& & & $935.8(3)$ \\
$9 \mathrm{~d}$ & $137.1(2)$ & $403.7(3)$ & $928.3(3)$ \\
$30 \mathrm{wk}$ & $135.0(2)$ & $496.7(3)$ & $>1080(6)$
\end{tabular}

LDL $(100 \mu \mathrm{g} / \mathrm{ml})$ was incubated in PBS and oxidation was initiated by adding $5 \mu \mathrm{M} \mathrm{Cu}^{2+}$. Lag times were determined as described in Methods. Values in parentheses are number of animals.

at the beginning of the study. However, because there was a large decrease in VLDL cholesterol in the probucol group ( 50\%), LDL accounted for a larger fraction of total plasma cholesterol at the end of the study. As discussed below, these shifts are relevant to the observed changes in drug concentration within lipoprotein particles.

The extent of sudanophilic lesions in the aortas of the three groups is shown in Table III. The quantification of surface lesion areas by digital imaging showed significantly less atherosclerosis in the probucol-treated animals compared with the control animals $(P<0.01)$. The total arterial surface area involved in lesions was reduced by almost $50 \%$. The reduction of arteriosclerosis was highly significant $(P<0.01)$ in all three segments of the aorta. The slowing of the atherosclerotic process was most pronounced in the descending thoracic aorta $(-71 \%)$. On the contrary, in rabbits treated with BM15.0639 the extent of aortic lesions was unchanged compared with the control group. The small differences in individual segments of the aorta were statistically not significant.

In an attempt to assess the extent to which the decrease in plasma cholesterol caused by probucol might have contributed to its observed antiatherogenic effect, a statistical analysis of variance with cholesterol as covariant was performed. Because there was no difference in lesion area between the control group and the analogue-treated group, the results in those two groups were pooled ( $32.8 \pm 6.9 \%$ of aortic surface covered by lesions).

Table III. Extent of Aortic Lesions in WHHL Rabbits after Treatment with BM15.0639 or Probucol

\begin{tabular}{lcccc}
\hline & \multicolumn{4}{c}{ Extent of aortic lesions } \\
\cline { 2 - 5 } \multicolumn{1}{c}{ Experimental group } & Total aorta & Arch & $\begin{array}{c}\text { Descending } \\
\text { thoracic }\end{array}$ & Abdominal \\
\hline & & \% of surface area involved \\
Untreated $(n=10)$ & $32.8 \pm 5.8$ & $66.0 \pm 11.6$ & $29.1 \pm 9.0$ & $19.2 \pm 4.1$ \\
BM15.0639 $(n=11)$ & $32.8 \pm 4.9$ & $71.5 \pm 13.8$ & $27.0 \pm 3.8$ & $17.9 \pm 3.9$ \\
Probucol $(n=6)$ & $17.8 \pm 3.8$ & $47.6 \pm 10.4$ & $8.4 \pm 9.4$ & $10.9 \pm 4.7$ \\
& & & & \\
\hline
\end{tabular}

Surface areas of sudanophilic lesions were determined by digital imaging and expressed as percentage of total arterial surface. Probucol treatment decreased the extent of arteriosclerotic lesions significantly $(P<0.01)$ compared with untreated and BM15.0639-treated animals. 
Table IV. Rates of LDL Degradation in the Aorta (fraction of plasma $L D L$ pool degraded $\times 10^{5}$ per $g$ of tissue per day)

\begin{tabular}{lclr}
\hline & Arch & \multicolumn{1}{c}{$\begin{array}{c}\text { Descending } \\
\text { thoracic }\end{array}$} & Abdominal \\
\hline Untreated $(n=4)$ & $24.8 \pm 3.6$ & $21.0 \pm 11.9$ & $10.9 \pm 1.9$ \\
BM15.0639 $(n=4)$ & $18.4 \pm 5.4$ & $21.5 \pm 12.6$ & $8.0 \pm 4.7$ \\
Probucol $(n=4)$ & $13.1 \pm 4.5$ & $10.0 \pm 8.9$ & $5.9 \pm 2.3$ \\
\hline
\end{tabular}

Analysis of variance with repeated measures was used to compare data between groups. Differences between probucol-treated and untreated animals were significant $(P=0.001)$. BM15.0639-treated animals were not different from untreated at $P=0.372$.

Before adjustment for plasma cholesterol levels, lesion area in the probucol-treated group was $17.8 \pm 3.8 \%$ and after adjustment $19.2 \%$. The latter was still significantly different from the value in the control group (32.4\% after adjustment) at the $P<0.01$ level.

Metabolism of LDL in the whole body and within the arterial wall was measured in three subgroups of four WHHL rabbits each. The rate of LDL catabolism in the whole body showed similar fractional catabolic rates (control rabbits, $0.016 \pm 0.001$ $\mathrm{h}^{-1}$; BM15.0639-treated rabbits, $0.015 \pm 0.001 \mathrm{~h}^{-1}$; probucoltreated rabbits, $0.012 \pm 0.002 \mathrm{~h}^{-1}$ ) The rate of LDL degradation within lesions, on the contrary, was significantly decreased in animals treated with probucol (Table IV). Animals treated with BM15.0639 showed no significant difference in fractional catabolic rates within lesions.

Drug levels in aortic tissue and histology. The concentrations of probucol and BM15.0639 in aortic tissue were determined in a separate set of animals after 2 and 18 wk of treatment. At both time intervals, the concentrations of the compounds were almost identical, both in normal aortic tissue and in lesioned areas. After $18 \mathrm{wk}$ of treatment both compounds were found at much higher concentrations within lesions than in normal aorta. The drug levels measured after $18 \mathrm{wk}$ are shown in Fig. 4.

The cellular composition of lesioned arterial tissue was examined by immunohistology. We used the monoclonal antibodies RAM-11, HHF-35, and MDA2, specific for macrophages, smooth muscle cells, and malondialdehyde-modified LDL, respectively. Comparing lesions at similar stages of development, no obvious treatment effect on cellular composition was seen. To examine the distribution of lipids within the arterial wall, frozen sections were prepared and stained with Sudan black B. A representative number of sections from all three segments of the aorta were analyzed. No obvious change in lipid distribution was found among the three treatment groups.

\section{Discussion}

These results confirm the effectiveness of probucol as an antiatherogenic drug in LDL receptor-deficient rabbits. As in previous studies (3-5), the probucol-treated animals showed about a $50 \%$ inhibition in the extent of lesions, and the LDL from these animals strongly resisted oxidative modification in vitro. As in the studies of Carew et al. (3), we were able to show that the rate of uptake of injected native LDL into atherosclerotic lesions was sharply reduced in the probucol-treated ani-

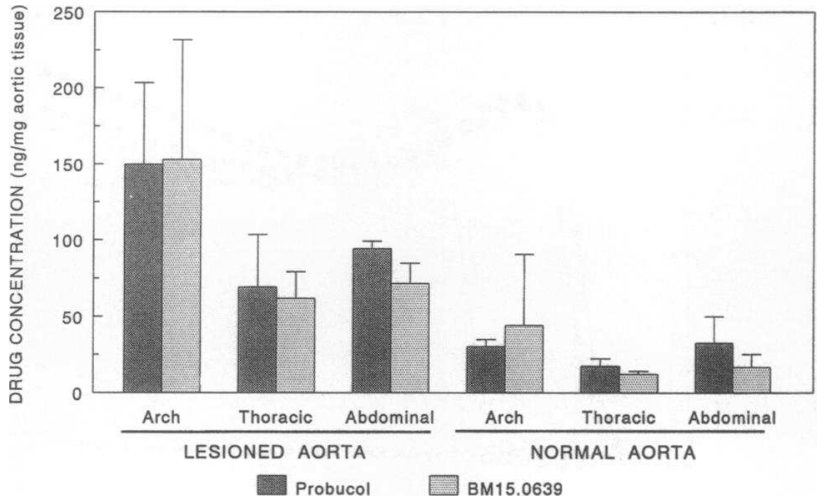

Figure 4. Concentration of probucol and BM15.0639 in aortic tissue. LDL receptor-deficient rabbits were fed a diet containing $1 \%$ probucol or $0.05 \%$ BM15.0639 for $18 \mathrm{wk}$. Aortas were removed and divided into arch, descending thoracic, and abdominal aorta. Drug concentrations in lesioned and unlesioned tissue were determined separately as described in Methods. The results shown are means of three animals per group.

mals. This is very likely because probucol inhibits oxidation of LDL, for the following reasons. First, earlier studies have shown that most of the uptake of injected native LDL into lesions in these rabbits is attributable to uptake into macrophages (30). Second, Watanabe rabbits express almost no functional native LDL receptors and, in any case, these would be expected to be downregulated in the face of the very high plasma LDL concentrations found. In fact, in situ hybridization studies (31) have shown that the LDL receptor is markedly downregulated in atherosclerotic lesions but that the acetyl LDL receptor is strongly expressed. Thus it seems reasonable to conclude that most of the uptake of injected native LDL into lesions in this and related studies is attributable to macrophage uptake via the acetyl LDL receptor, which means the LDL must have been first converted from the native form to the oxidatively modified form. Probucol would be expected to inhibit this conversion and the decreased incorporation into lesions in the probucoltreated animals is consistent with this interpretation. Alternative interpretations, however, are possible as discussed below.

The probucol analogue studied here (BM15.0639) was just as effective as an antioxidant in vitro as probucol. Because of the much greater bioavailability of the analogue and because we wanted to try to achieve comparable plasma levels of the two compounds, the analogue was fed at only $0.05 \%$ in the diet whereas probucol was fed at $1 \%(\mathrm{wt} / \mathrm{wt})$. The total plasma concentrations of the two drugs at the end of the studies were in fact about the same. Lesion development, however, was not affected by the treatment with BM15.0639. The rates of LDL degradation within arterial lesion sites of BM15.0639-treated rabbits was also not significantly different from control animals, suggesting that oxidation of LDL was not being inhibited. LDL isolated from plasma of the analogue-treated animals at the end of the study was protected against oxidation, but not nearly as well as LDL from probucol-treated rabbits. Whereas probucol prolonged the diene conjugation lag time to values of $\geq 1,000$ $\mathrm{min}$, the analogue only extended the lag time to $\sim 400 \mathrm{~min}$ (compared with the normal value of $130 \mathrm{~min}$ ). Although the total plasma concentrations were similar, the number of molecules of probucol per LDL particle was twice the number of analogue molecules per particle. This was accounted for by two 
factors: $(a)$ the total plasma cholesterol of the probucol-treated animals fell by $25 \%$ so that the drug was distributed into a smaller total number of lipoprotein particles than in the case of the analogue-treated group and $(b)$ the fraction of the total plasma cholesterol present in the LDL fraction increased by almost $50 \%$. The latter was mainly due to a large drop in VLDL cholesterol. Thus, the larger number of probucol molecules in the LDL may be enough to explain the difference in degree of protection against oxidation. It is also possible that metabolites of probucol carried in LDL (not measured in these studies) may make a contribution to the protection against oxidation seen in the probucol-treated group. The analogue probably is not metabolized in the same way as probucol. Lacking the sulfur atoms in the bridge (see Fig. 1), its metabolism may be limited to the aromatic rings. Whereas metabolites of probucol were detected by HPLC, no metabolites of BM15.0639 were noted. Whatever the mechanism involved, the key question is whether the difference in degree of protection against oxidative modification ex vivo is sufficient to explain the ineffectiveness of the analogue in slowing the progression of atherosclerotic lesions. Compatible with this conclusion is the fact that the incorporation of injected native LDL into arterial lesions was not inhibited in the analogue-treated rabbits.

Little or no information is available that relates effectiveness of antioxidants in vitro to their antiatherogenic potential. We do not know whether there is a graded relationship or a threshold relationship. The latter possibility is a real one. Consider the transport of LDL into and out of the arterial wall. LDL particles will on the average reside within the artery wall for some defined time interval (mean residence time). Schwenke and Carew (32) have estimated the mean residence time of LDL particles in the normal rabbit aorta and in the aorta of animals with experimental atherosclerosis. Under normal conditions, with a short residence time within the artery wall, LDL might undergo very little oxidative damage during transit. Once it reenters the plasma compartment, the chances that it will reenter the artery are extremely small, since only a very small fraction of LDL turnover is attributable to arterial uptake. If the degree of oxidation of a particular LDL particle goes beyond a certain point during its passage through the artery wall, that LDL may become a target for uptake via scavenger receptors or it may undergo complexing with connective tissue matrix, or it may aggregate with other LDL particles. In that case, its fate may be to stay indefinitely within the artery wall and wind up being taken up by macrophage scavenger receptors. The central point here is that in order to be effective, an antioxidant residing in the LDL particle may need to protect it for a length of time near to or greater than the residence time of LDL within the artery wall. That time may not be the same as the diene conjugation lag time in absolute terms, because the latter is measured under artificial in vitro conditions that may or may not reflect the pro-oxidant "stress" within the artery wall, but there might be some proportionality. It is conceivable that there is a threshold level of protection that would represent the minimum necessary to exert an antiatherogenic effect. In this connection, a recently completed study of the effectiveness of probucol in Macaca nemestrina may be pertinent. Sasahara and co-workers (33) showed that probucol (1\% wt/wt in the diet) inhibited lesion formation by $\sim 50 \%$ in the thoracic aorta $(P<0.001)$. No effects were seen in the abdominal aorta nor in the iliac arteries, possibly because lesions were more advanced in these arterial segments. The investigators measured diene conjugation lag time in the LDL isolated from these animals at the end of the study. What they found was that there was a negative correlation between the extent of lesion area and the prolongation of the diene conjugation lag time. They suggested that diene conjugation lag times needed to be $\geq 400 \mathrm{~min}$ in order to significantly inhibit lesion formation. This value is near the diene conjugation lag time achieved with the analogue in the present studies, an effect that was not associated with inhibition of lesion formation. This should not be overinterpreted because of the species difference but the coincidental finding of a similar "threshold" in prolongation and lag time is worth noting.

Although the proposed antioxidant mechanism is appealing, it is still unclear whether this is the major underlying mechanism of probucol's action. This is especially true, because BM15.0639 failed to slow the progression of atherosclerosis despite protecting LDL against oxidation ex vivo. The degree to which LDL was protected was remarkably high compared with maximally achievable protection with natural antioxidants, such as vitamin E. Probucol has a number of additional effects which therefore need to be considered. First, probucol does have a cholesterol-lowering effect and cholesterol levels were somewhat lower in the probucol-treated group. However, the difference was small and, as discussed above, correction for the effect of the degree of hypercholesterolemia on the extent of lesion formation accounts for only a very small part of the probucol effect in lesion formation. In the studies of Carew et al. (3) the control rabbits were treated with a small dose of lovastatin, just enough to match the plasma cholesterol levels in those treated with probucol. Thus, a difference in cholesterol levels did not contribute to the antiatherogenic effect of probucol in those studies. In the studies of Sparrow et al. (8), using DPPD, and the studies by Björkhem et al. (7), testing BHT, there were no differences in cholesterol level and the effectiveness of those two antioxidants in cholesterol-fed rabbits is clearly not due to a cholesterol-lowering effect. For all of these reasons it does not seem likely that the different results in the present studies are due to the small decrease in cholesterol levels induced by probucol.

A second category of explanation for the difference in effectiveness of the two compounds against atherogenesis is that probucol has additional biological properties that may not shared by the analogue. As pointed out in the introduction, several of these properties could be relevant to its antiatherogenic effect $(12-15)$. The analogue has not yet been tested to determine whether it shares these properties with probucol.

Whatever the explanation of the unexpected ineffectiveness of BM15.0639 against atherogenesis, these negative results are instructive. Many investigators, including ourselves, have tended to assume that the relative effectiveness of antioxidants as antiatherogenic agents would parallel their effectiveness in protecting LDL in ex vivo measurements of oxidation under controlled conditions. Clearly things are more complex. Much more work is needed to sort out what the true relationship is and to search for other relevant variables.

\section{Acknowledgments}

We are most grateful to Mercedes Silvestre, Jennifer Pattison, Stephen Palmer, and Simone Green for their technical assistance. We acknowledge the help of Dr. W. F. Beltz with the statistical analysis and of Dr. W. Palinski with the histological studies. We thank Prof. Dr. K. Strein and Boehringer Mannheim (Mannheim, Germany) for their generous support of these studies. 
This work was supported by grant HL-14197 from the National, Heart, Lung, and Blood Institute (Specialized Center of Research on arteriosclerosis) and by the Stein Institute for Research on Aging. J. Fruebis was supported by a grant from Boehringer Mannheim.

\section{References}

1. Steinberg, D., S. Parthasarathy, T. E. Carew, J. Khoo, and J. L. Witztum. 1989. Beyond cholesterol: modifications of low-density lipoprotein that increase its atherogenicity. N. Engl. J. Med. 320:915-924.

2. Witztum, J. L., and D. Steinberg. 1992. Role of oxidized low density lipoprotein in atherogenesis. J. Clin. Invest. 88:1785-1792.

3. Carew, T. E., D. C. Schwenke, and D. Steinberg. 1987. Antiatherogenic effect of probucol unrelated to its hypocholesterolemic effect: Evidence that antioxidants in vivo can selectively inhibit low density lipoprotein degradation in macrophage-rich fatty streaks and slow the progression of atherosclerosis in the Watanabe heritable hyperlipidemic rabbit. Proc. Natl. Acad. Sci. USA. 84:77257729.

4. Mao, S. J. T., M. T. Yates, R. A. Parker, E. M. Chi, and R. L. Jackson. 1991. Attenuation of atherosclerosis in a modified strain of hypercholesterolemic Watanabe rabbits with use of a Probucol analogue (MDL 29,311) that does not lower serum cholesterol. Arteriosclerosis and Thrombosis. 11:1266-1275.

5. Kita, T., Y. Nagano, M. Yokode, K. Ishii, N. Kume, A. Ooshima, H. Yoshida, and C. Kawai. 1987. Probucol prevents the progression of atherosclerosis in Watanabe heritable hyperlipidemic rabbit, an animal model for familial hypercholesterolemia. Proc. Natl. Acad. Sci. USA. 84:5928-5931.

6. Daugherty, A., B. S. Zweifel, and G. Schonfeld. 1991. The effects of probucol on the progression of atherosclerosis in mature Watanabe heritable hyperlipidemic rabbits. Br. J. Pharmacol. 103:1013-1018.

7. Björkhem, I., A. Henriksson-Freyschuss, O. Breuer, U. Diczfalusy, L. Berglund, and P. Henriksson. 1991. The antioxidant butylated hydroxytoluene protects against atherosclerosis. Arteriosclerosis and Thrombosis. 11:15-22.

8. Sparrow, C. P., T. W. Doebber, J. Olszewski, M. S. Wu, J. Ventre, K. A Stevens, and Y. S. Chao. 1992. Low density lipoprotein is protected from oxidation and the progression of atherosclerosis is slowed in cholesterol-fed rabbits by the antioxidant $N, N^{\prime}$-diphenyl-phenylenediamine. J. Clin. Invest. 89:1885-1891.

9. Daugherty, A., B. S. Zweifel, and G. Schonfeld. 1989. Probucol attenuates the development of aortic atherosclerosis in cholesterol-fed rabbits. Br. J. Pharmacol. 98:612-618.

10. Stein, Y., O. Stein, B. Delplanque, J. D. Fesmire, D. M. Lee, and P. Alaupovic. 1989. Lack of effect of probucol on atheroma formation in cholesterolfed rabbits kept at comparable plasma cholesterol levels. Atherosclerosis. 75:145155.

11. Verlangieri, A. J., and M. J. Bush. 1992. Effects of $d$-alpha-tocopherol supplementation on experimentally induced primate atherosclerosis. J. Am. Coll. Nutr. 11:131-138.

12. Ku, G., N. S. Doherty, J. A. Wolos, and R. L. Jackson. 1988. Inhibition by probucol of Interleukin-1 secretion and its implication in atherosclerosis. Am. J. Cardiol. 62:77B-81B.

13. Franceschini, G., G. Chiesa, and C. R. Sirtori. 1991. Probucol increases cholesterol ester transfer protein activity in hypercholesterolemic patients. Eur. J. Clin. Invest. 21:384-388.

14. McPherson, R., M. Hogue, R. W. Milne, A. R. Tall, and Y. L. Marcel. 1991. Increase in plasma cholesterol ester transfer protein during probucol treatment. Relation to changes in high density lipoprotein composition. Arteriosclerosis and Thrombosis. 11:476-481.
15. Parthasarathy, S. 1992. Evidence for an additional intracellular site of action of probucol in the prevention of oxidative modification of low density lipoprotein. J. Clin. Invest. 89:1618-1621.

6. Nierenberg, D. W., and S. L. Nann. 1992. A method for determining concentrations of retinol, tocopherol, and five carotenoids in human plasma and tissue samples. Am. J. Clin. Nutr. 56:417-426.

17. Havel, R. J., H. A. Eder, and J. H. Bragdon. 1955. The distribution and chemical composition of ultracentrifugally separated lipoproteins in human serum. J. Clin. Invest. 34:1345-1353.

18. Lowry, O. H., N. J. Rosebrough, A. L. Farr, and R. J. Randall. 1957. Protein measurement with the Folin phenol reagent. J. Biol. Chem. 226:497-509.

19. Sparrow, C. P., S. Parthasarathy, and D. Steinberg. 1989. A macrophage receptor that recognizes oxidized low density lipoprotein but not acetylated low density lipoprotein. J. Biol. Chem. 264:2599-2604.

20. Palinski, W., V. A. Ord, A. S. Plump, J. L. Breslow, D. Steinberg, and J. L. Witztum. 1994. Apoprotein E deficient mice are a model of lipoprotein oxidation in atherogenesis: demonstration of oxidation-specific epitopes in lesions and high titers of autoantibodies to malondialdehyde-lysine in serum. Arterioscle rosis and Thrombosis. 14:605-616.

21. Pittman, R. C., T. E. Carew, C. K. Glass, S. R. Green, C. A. Taylor, and A. D. Attie. 1983. A radioiodinated, intracellularly trapped ligand for determining the sites of plasma protein degradation in vivo. Biochem. J. 212:791-800.

22. Schwenke, D. C., and T. E. Carew. 1988. Quantification in vivo of increased LDL content and rate of LDL degradation in normal rabbit aorta occurring at sites susceptible to early atherosclerotic lesions. Circ. Res. 62:699-710.

23. Carew, T. E., R. C. Pittman, E. R. Marchand, and D. Steinberg. 1984. Measurement in vivo of irreversible degradation of low density lipoprotein in the rabbit aorta. Predominance of intimal degradation. Arteriosclerosis. 4:214-224.

24. Tsukada, T., M. Rosenfeld, R. Ross, and A. M. Gown. 1986. Immunocytochemical analysis of cellular components in lesions of Watanabe and fat-fed rabbits using monoclonal antibodies. Arteriosclerosis. 6:601-613.

25. Ross, R., and B. Kariya. 1980. Morphogenesis of vascular smooth muscle in atherosclerosis and cell culture. In: Handbook of Physiology. Vol. 7. American Physiological Society, Bethesda, MD. 69-91.

26. Palinski, W., S. Ylä-Herttuala, M. E. Rosenfeld, S. W. Butler, S. A Socher, S. Parthasarathy, L. K. Curtiss, and J. L. Witztum. 1990. Antisera and monoclonal antibodies specific for epitopes generated during oxidative modification of low density lipoprotein. Arteriosclerosis. 10:325-335.

27. Rosenfeld, M. E., W. Palinski, S. Ylä-Herttuala, S. Butler, and J. L. Witztum. 1990. Distribution of oxidation specific lipid-protein adducts and apolipoprotein B in atherosclerotic lesions of varying severity from WHHL rabbits Arteriosclerosis. 10:336-349.

28. Sheehan, D. C., and B. B. Hrapchak. 1980. Theory and Practice of Histotechnology. Battelle Press, Colombus, $\mathrm{OH}$

29. BMDP Statistical Software Manual. 1985. University of California Press Berkeley, CA.

30. Rosenfeld, M. E., T. E. Carew, E. Hodenberg, R. C. Pittman, R. Ross, and D. Steinberg. 1992. Autoradiographic analysis of the distribution of ${ }^{125} I$ Tyramine-Cellobiose-LDL in atherosclerotic lesions of the WHHL rabbit. Arteriosclerosis \& Thrombosis. 12:985-995.

31. Ylä-Herttuala, S., M. E. Rosenfeld, S. Parthasarathy, E. Sigal, T. Särkioja, J. L. Witztum, and D. Steinberg. 1991. Gene expression in macrophage-rich human atherosclerotic lesions. J. Clin. Invest. 87:1146-1152.

32. Schwenke, D. C., T. E. Carew. 1989. Initiation of atherosclerotic lesions in cholesterol-fed rabbits. Arteriosclerosis. 9:908-918.

33. Sasahara, M., E. W. Raines, A. Chait, T. E. Carew, D. Steinberg, D. W. Wahl, and R. Ross. 1994. Inhibition of hypercholesterolemia-induced atherosclerosis in the nonhuman primate by probucol: is the extent of atherosclerosis related to resistance of LDL to oxidation? J. Clin. Invest. In press. 